\title{
Green Feelings in Animated Movies Directed by Miyazaki Hayao
}

\author{
Yuexiu Wang \\ Dalian Neusoft University of Information \\ Dalian, China
}

\author{
Ran Zhao \\ Dalian Neusoft University of Information \\ Dalian, China
}

\begin{abstract}
Green feeling is a broad mind which values nature, life, emotion and freedom and advocates the coexistence of haven, earth, human being and god. It is focused on the living conditions and harmonious development between human being and nature, human beings and so on. As a leading figure in directing animation in Japan, and the animated movie themes that he directs are mainly targeting human being development, ecological nature, environmental protection, anti-war and peace, concerning about the fate of human being and the like. He shows the green feeling of his own through eyes of animator, super technique and child interest, which make the animated movies that he directs full of depth in thought and great power. Based on the animated movies that Miyazaki Hayao directs, this article analyzes green elements used in the animated movies.
\end{abstract}

Keywords-green feeling; Miyazaki Hayao; harmonious; nature; animated movie

\section{INTRODUCTION}

An animated movie is a form of art profound and independent and the animation director shall be soul of the movie. And the director's creative intension, background, figure's characters, story structure, picture treatment as well as the grasp of scene rhythm are key points for producing the movie. Japanese animated movies are popular relying on aesthetic style, graceful character shape, connotation-rich dialogue and plots, Miyazaki Hayao, an outstanding director in Japanese animation, has created an aesthetic, natural and fresh style of his own. The animated movies directed by Miyazaki Hayao have stricken a line of his own in the field of animated movies around the world relying on exquisite technique, heartfelt story and exquisite sensibility. Most of the animated movies are based on relations between human and nature, humans as well as harmonious development, indicating the harmonious co-existence of haven, earth, human and god and showing his strong green feeling. And the movies that he directs reach the bottom the audients' hearts, enlightening the people to think what the life is.

Green elements can be found in every animated movie directed by Miyazaki Hayao, here the "green" has diverse meanings, including a narrow sense and a broad sense. Seen from the narrow sense, the green refers to a hue, a color, a common color of plants and also one often shown in the animated movies directed by Miyazaki Hayao; whether the broad green lands, green rice, green forestry or green hills and mountains even the green belts dotted at downtown areas, the green belts bring audiences visual enjoyment, followed by mental pleasure, and a feeling refreshing and vivifying just arise out of the hearts, lasting for a long time. Seen from the broad sense, the green has more connotations, for example, the green stands for peace for the world; the green symbolizes harmony and energy in China, which can be found in the five elements, an intention of wood among metal, wood, water, fire and soil. For being related to spring, the green stands for youth and prosperity, in character, green stands for peace and kindness; green is typical color of plants, so green stands for nature, ecology and environmental protection.

This author here analyzes the green elements shown in the animated movies directed by Miyazaki Hayao through different angles in the following:

\section{SCENARIO SOURCE OF ANIMATED MOVIES - GREEN LITERATURE}

Speaking generally, green literature takes natural animals and plants as themes where life awareness is stressed. Specifically, the green literature advocates the life awareness, vigorous vitality of nature and human as well as harmony and co-existence between human and nature.

The stories of animated movies directed by Miyazaki Hayao do not adhere to a given form, and there are abundant materials available, whether the tales, myths, poems, novels and picture books in Japan or around the world, all are sources of the inspiration for his creation. All stories of the movies directed by Miyazaki Hayao value life and advocate green literature showing the harmony and co-existence between human and nature.

Typical animated movies directed by Miyazaki Hayao include:

Nausicaä of the Valley of the Wind was reorganized by Miyazaki Hayao in 1984 according to the cartoon with the same name. In the movie, relations between human and nature, human and creature and humans are important elements, within the complicated relations, heroine Nausica weighted and finally helped human find a way for coexistence between humans, human and insects.

Castle in the Sky was directed by Miyazaki Hayao and produced by Japanese Studio Ghibli in 1986, it was a movie 
filled with humanity and fight. Heroine Sheeta and hero Pazu were kind juveniles, who fought against those who were controlled by greed, trying to save the legendary Castle in the Sky Laputa. In the movie, the Laputa was covered with vegetations vibrant, compared to the scene of industrial revolutionary in Europe such as elevated rails, old trains, dark mines and so on. And the relations between humans, human and nature are worth deeply thinking.

Thirteen years ago, though the Nausicaä of the Valley of the Wind was a great success, yet it debarred the animated movies directed by Miyazaki Hayao to break through, and animators and directors were hard to go out of the castle of their own. After summarizing years of thoughts about relations between human and nature, Miyazaki Hayao decided to direct a new works Princess Mononoke in 1997, ending the hesitation in attitude and rejecting the rules established before, achieving an upgrade and going to think and explore at a wider scope for human and nature. The Princess Mononoke proved a success, in the movie the theme was the relations between human and nature, stating a story where human destroyed the nature in order to develop technologies and caused revenges with a high price. And the hero Ashitaka has been seeking a way for the co-existence between human and forestry.

In 2008, Miyazaki Hayao wrote and directed a long animated movie Ponyo on the Cliff, which described a story where a mermaid Ponyo who lived in the deep sea was longing for human life and wanted to become a human in order to live with a little boy Sousky. In the film, Miyazaki Hayao also expressed his opinion about the relations between human development natural ecology of his own that is a harmonious coexistence for human and nature. On the other hand, the movie shows the good side of human nature, and warm scenes were shown many times, which fully demonstrated the goodness, optimism, understanding, mutual aid, kindness, inclusiveness of humanity and so on.

\section{THEMES OF ANIMATED MOVIES - GREEN AND ENVIRONMENT FRIENDLY}

Green is closely related to nature and plants, which contain connotation of freshness and vitality, as well as life, able to stand for natural, ecology and environmental protection and so on.

Environmental protection and energy conservation and emission reduction are hot topics attracting eyes of the world. Currently many countries have established "green plans", a green planet plant to prevent the global warming and through environmental protection and low-carbon energy-saving.

Within movies directed by Miyazaki Hayao, there were also discussions on relations between human and nature, and Nausicaä of the Valley of the Wind, Castle in the Sky, The Raccoon War, Princess Mononoke and Ponyo on the Cliff were the best to show the author's love to the nature and worries about the industrialization of human society.

The movie Nausicaä of the Valley of the Wind in 1984 described a coming desertified world. The overdevelopment by human has reduced the forest areas, and the lands are seriously desertified. Human thought the nature would be conquered for booming. However, after the war "Seven-day fire" broke, the industrial civilization paid a high price for it. The movie Castle in the Sky in 1986 showed us two comparative environmental landscapes: first, industrialization of human world on the ground; second, Laputa, a castle in the sky, a calm haven city in the sky guarded by robots, a paradise of plants and ancient creatures. The movie Raccoon War in 1994 told us a story that with the enlargement of industrialization of human being, the living spaces and environment of raccoons were destroyed, and the raccoons decided to restore the magic of their ancestors to fight against human being, the whole movie was warmhearted and full of imagination, and the thick colors carried Japanese folkways. Though the raccoons tried what they could to be human and live among the human being, without magic, they could only survive the artificial landscapes. The movie Princess Mononoke in 1997 is a personalized animated movie that the relations between human and nature were thought since childhood. The story happed in the medieval era of Japan, a stage of transition where human seriously seized and destroyed the environment in order for development. The story started with the natural contradiction that cannot be solved between human being and nature to seek whether human being and nature could live in harmony from the survival of human being. The movie Ponyo on the Cliff showed the author's love to the nature and worries about the industrialization of human society.

\section{BACKGROUND OF ANIMATED MOVIES - GREEN SCENE}

Green is a necessary factor for the animated movies directed by Miyazaki Hayao, which shows his love to nature.

In 1986, the animated movie Nausicaä of the Valley of the Wind described a Laputa in a wasted city in the sky, which was protected by robots generations by generations, and the animas and plants protected formed a beautiful city in the sky. In 1988, the movie My Neighbor Totoro described beautiful scenes in villages. In 1977, the movie Princess Mononoke described lush and green forest for Kylin. In 2001, the movie Spirited Away described a unique and beautiful natural landscape. In 2004, Howl's Moving Castle described a beautiful flowery house which was charming. In 2008, the movie Ponyo on the Cliff described a beautiful scene in deep sea.

\section{STORY EXPRESSION OF ANIMATED MOVIES-GREEN CULTURE}

Green culture also has senses narrow and broad: Seen from the narrow sense, green culture can achieve the coordinated development, harmonious development between human and natural environment and can guarantee the sustainable development of human society; seen from the broad sense, green culture is a culture where green plants are symbols created by human in order to adapt to the environment, including collecting-hunting culture, agriculture, forestry and urban greening as well as all plant 
sciences. The animated movies directed by Miyazaki Hayao promote green culture and advocate the coordinated development and harmonious progress between human and natural environment. Nausicaä of the Valley of the Wind, Castle in the Sky and Ponyo on the Cliff all showed the thought of Miyazaki Hayao to express the green culture where nature and human are harmonious for development.

\section{Metaphor Meaning of Animated Movies- GREEN RELATIONS}

International organizations which value ecological environment commonly adopt green as a typical color, such as green peace. Thus a new word "green relationship" comes into being, it mainly refers to the mutual benefits between people for coordinated development. Many stories in the animated movies directed by Miyazaki Hayao reflected the author's feeling of needing green relations. What he wanted to show audiences are anti-war and seeking co-existence.

The blue planet where human beings live together is just like a green relation of the nature, which is closely related to each other, needing mutual independence, anyone cannot live alone, for the world is owned by someone alone. With the thought "We are together", can human know how to cherish, cooperate and ally? Respect the existence of individuals, keep mutual understanding and inclusive and allow the existence of different views so as to create good green relations.

The hero in Porco Rosso would rather be a pig than fight, which showed the author's thirst for green relations.

In the movie Howl's Moving Castle, Howl turned into a huge bird fighting for the country, expecting to lower the injuries as possible as he can, which showed the thought of anti-war of Miyazaki Hayao.

\section{TRANSMISSION OF ANIMATED MOVIES - GREEN BEHAVIORS}

Green behavior, also known as green life action, refers to a life way and action where it starts from the doer, driving the smallest unit in society - home so as to promote the development of the society, change the past inappropriate life and consumption modes, promote low-carbon and environment friendly consumption, achieve the harmonious development and re-create a life way and action to protect the environment, save resources and protect the ecological balance, which are also an embodiment of noble moral and behavioral civilization. Miyazaki Hayao promoted the green action through animations, starting from himself to drive audiences to understand the green actions and resonate potentially so as to reflect some bad behaviors.

\section{IMPRESSION OF ANIMATED MOVIES - GREEN MENTALITY}

British University of Essex ever conducted a survey, and the results showed that green is a special color, which is neither a part of cold color nor a warm color, belonging to a medium color. Meanwhile, green can increase the sense of comfort, relieve fatigue, bringing senses of freshness, hope, calmness safety in vision, meanwhile it stands for the nature, for primitive humans, the green environment means adequate food and water, and the positive feeling to green was integrated to the human brains during the evolution and preserved till now. In a green environment, people feel high, full of vitality and pleasure. All animated movies directed by Miyazaki Hayao contains multi-level green, therefore after watching the animated movies, we often feel comfortable and pleasant.

\section{CONCLUSION}

In a word, as an internationally famous master of animation, Miyazaki Hayao has shown us a series of animated movies like hand painting, in his works, nature, folklore, culture, humanity and ties of matters are crossed and mixed each other, and the themes are upgrade to the height of spirit, and the animated movies succeeded in achieving an all-age span, able to transmit the thought "different people have different opinions", and the green feelings he showed in the movies have affected the whole world and human.

\section{REFERENCES}

[1] Zhang Rongli, Analysis of Metaphor from Memes [D] Heilongjiang University, 2008, p37.

[2] Zhang Rongli, Analysis of Metaphor from Memes [D] Heilongiang University, 2008, p37.

[3] Zhong Xiangming, Zhong Kangyun, Analysis of New Animation Ponyo on the Cliff Directed by Miyazaki Hayao [J] Press Circles, 2009.10:199-200.

[4] Zhong Xiangming, Zhong Kangyun, Analysis of New Animation Ponyo on the Cliff Directed by Miyazaki Hayao [J] Press Circles, 2009.10:199-200.

[5] Jiang Xianghui, Ding Jinghui, Studies on Literal Narration in Nausicaä of the Valley of the Wind $[\mathrm{J}]$ Movie Literature, 2017.01:110-112.

[6] He Juan, Guanz Theory of Governance, Green Moral Theory and China Dream [C] The 2014 9th Nationwide Seminar on Guanzi Theory, 2014.05:62-66

[7] He Juan, Guanzi Theory of Governance, Green Moral Theory and China Dream [C] The 2014 9th Nationwide Seminar on Guanzi Theory, 2014.05:62-66. 